\title{
Coded Ordinal Data Type
}

National Cancer Institute

\section{Source}

National Cancer Institute. Coded Ordinal Data Type. NCI Thesaurus. Code C95633.

A data type comprised of coded values that are associated with a specific order. (ISO) 